\title{
Factors associated with cognitive impairment in a Mexican multicenter Parkinson's disease cohort: a cross-sectional comparative study
}

\author{
Daniel Martínez-Ramírez, ${ }^{*}$ Amin Cervantes-Arriaga, ${ }^{2}$ David Garza-Brambila, ${ }^{1}$ Karla Salinas-Barboza, ${ }^{3}$ \\ Sara Isaís-Millán, ${ }^{4}$ Antonio Anaya-Escamilla, ${ }^{5}$ Edna Sophia Velázquez-Ávila, ${ }^{1}$ Alejandro Banegas-Lagos, ${ }^{1}$ \\ Arnulfo Gonzalez-Cantúb and Mayela Rodríguez-Violante ${ }^{2}$

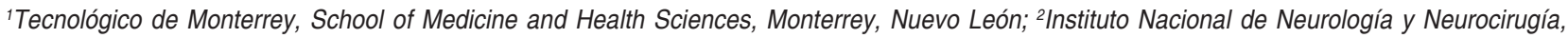 \\ Clinical Laboratory for Neurodegenerative Diseases, Mexico City; ${ }^{3}$ Ministry of Health, Hospital General de México, Mexico City; ${ }^{4}$ Instituto de Sguridad \\ y Servicios Sociales de los Trabajadores del Estado, Hospital Regional General "Ignacio Zaragoza", Mexico City; ${ }^{5}$ Christus Muguerza Hospital Sur, \\ Nuevo León; ${ }^{6}$ HospitalChristus Muguerza Alta Especialidad, Monterrey, Nuevo León. Mexico
}

\begin{abstract}
Introduction: Cognitive impairment is common in Parkinson's disease and represents a risk for dementia. Identifying associated factors will help implement early interventions and study its progression. Objective: To identify factors associated with cognitive impairment. Method: Cross-sectional study of 306 subjects with Parkinson's disease who were assessed for 12 months. Demographics and clinical variables were analyzed as explanatory variables, and cognitive impairment as outcome variable. Significant variables were used to construct a cognitive impairment predictive model. Results: Cognitive impairment was reported in $43.8 \%$. Female gender ( $p=0.001$, odds ratio [OR $=1.77)$, age at diagnosis $(p<0.001$, mean deviation [MD $=5.7$, level of education $(p<0.001, M D=-2.9)$, disease duration $(p=0.003, M D=1.7)$ MDS-UPDRS part III score $(p<0.001, M D=9.7)$, presence of anxiety $(p=0.007, O R=2.11)$, hallucinations $(p=0.029, O R=2.27)$ and freezing of gait $(p=0.048, O R=1.91)$ were predictors for cognitive impairment. The use of type $B$ monoamine oxidase inhibitors was associated with less cognitive impairment $(p=0.001)$. Conclusions: Predictive factors that were consistent with those previously reported were identified. Prospective studies are required in order to clarify the effect of type $B$ monoamine oxidase inhibitors on cognition.
\end{abstract}

KEY WORDS: Cognitive impairment. Non-motor symptoms. Parkinson's disease. Monoamine oxidase inhibitors.

\section{Factores asociados con deterioro cognitivo en una cohorte mexicana multicéntrica de Parkinson: estudio transversal comparativo}

\section{Resumen}

Introducción: El deterioro cognitivo en Parkinson es común y representa un riesgo para demencia. Identificar los factores asociados ayudará a implementar intervenciones tempranas y estudiar la progresión del deterioro cognitivo. Objetivo: Identificar factores asociados con deterioro cognitivo. Método: Estudio transversal de 306 sujetos con Parkinson evaluados durante los últimos 12 meses. Se estudiaron variables demográficas y clínicas como explicativas y el deterioro cognitivo como desenlace. Las variables significativas se utilizaron para construir un modelo predictor de deterioro cognitivo. Resultados: El $43.8 \%$ reportó deterioro cognitivo. El sexo femenino $(p=0.001, R M=1.77)$, edad al diagnóstico $(p<0.001$, desviación media [DM] 5.7), escolaridad ( $p<0.001, D M-2.9)$, duración de enfermedad ( $p=0.003, D M 1.7)$, puntuación en MDS-UPDRS 
parte III ( $p<0.001, D M 9.7)$, presencia de ansiedad $(p=0.007, R M=2.11)$, de alucinaciones $(p=0.029, R M=2.27)$ y congelamientos de la marcha $(p=0.048, R M=1.91)$ fueron predictores para deterioro cognitivo. El uso de inhibidores monoamina-oxidasa tipo $B$ se asoció con menor deterioro cognitivo $(p=0.001)$. Conclusiones: Se identificaron factores predictores consistentes con lo reportado previamente. Se requieren estudios prospectivos para aclarar el efecto de los inhibidores monoamina-oxidasa tipo $B$ en la cognición.

PALABRAS CLAVE: Deterioro cognitivo. Síntomas no motores. Parkinson. Inhibidores de monoaminooxidasa.

\section{Introduction}

Parkinson's disease (PD) is a complex neurodegenerative disorder characterized by classic motor symptoms such as bradykinesia, resting tremor, rigidity ${ }^{1}$ and a wide variety of non-motor symptoms that may occur during the course of the disease, including cognitive dysfunction. ${ }^{2}$ In PD, cognitive dysfunction can vary from mild cognitive impairment $(\mathrm{MCl})$ to dementia. $\mathrm{MCl}$ in PD has been reported in 18.9 to $57.1 \%$ of patients. ${ }^{3,4}$ In previous studies of Mexican PD cohorts, a prevalence of cognitive impairment of 39 to $41.3 \%$ was reported. ${ }^{5,6}$ The $\mathrm{MCl}$ profile in PD is mainly characterized by executive dysfunction, attention and visuospatial skills alterations, in addition to episodic memory problems and difficulty to find words. ${ }^{7}$ In addition, $\mathrm{MCl}$ predicts the development of dementia, which can occur in up to $80 \%$ of the population with PD during the course of the disease, ${ }^{8}$ where the development of dementia is significant and has a substantial impact on independence, admission to nursing homes, psychiatric comorbidities, burden for the caregiver, and mortality risk. ${ }^{9,10}$

Recent studies have reported demographic and clinical risk factors for cognitive impairment in PD such as age at onset, depression, anxiety, level of education, baseline measurements of disease severity, gender, olfactory dysfunction and hallucinations. ${ }^{11-14}$ In addition to clinical characteristics, associated factors have also been found: mutations (B-glucocerebrosidase gene), ${ }^{15}$ thinning of the cerebral cortex, ${ }^{16}$ cerebral white matter lesions ${ }^{17}$ and cerebral amyloid load. ${ }^{18}$ For this reason, we consider early recognition of cognitive impairment in PD to be of vital importance in order for strategies to reduce these outcomes to be implemented. With the purpose to identify factors associated with cognitive impairment in our population, we analyzed demographic and clinical variables, which will help to increase the knowledge about cognitive impairment risk factors and the possibility to detect subjects at risk for developing dementia in the course of the disease and, in addition, it will provide bases for future prospective study designs.

\section{Method}

Cross-sectional, descriptive, analytical, observational clinical study, to examine and identify factors associated with symptoms of cognitive impairment in a sample of Mexican subjects with PD. The study subjects were selected from the Mexican Parkinson Study Group cohort, constituted by 306 subjects with PD assessed during 2017 and 2018 and consecutively included. A neurologist specialist in movement disorders established the PD diagnosis according to criteria of the Movement Disorder Society (MDS). ${ }^{19}$ The subjects come from five Parkinson and movement disorders clinics of the country: Technological Institute of Monterrey, Christus Muguerza High Specialty and Christus Muguerza Southern Hospital of Monterrey, General Hospital of Mexico, Regional Hospital of the Institute of Social Security and Services of State Workers and National Institute of Neurology and Neurosurgery, Mexico. All subjects of the Mexican Parkinson Study Group cohort were included for analysis. The present study was approved by the institutional ethics committee.

For explanatory variables, demographic and clinical characteristics of the subjects were documented. Demographic characteristics included gender, current age, age at diagnosis and years of education. Clinical characteristics included disease duration, side of symptom onset (right, left, bilateral), PD motor subtype: tremor-dominant, postural instability with gait difficulty, intermediate, Hoehn and Yahr stage, drugs used (levodopa, dopaminergic agonists and types thereof [pramipexole or rotigotine, catechol-O-methyltransferase inhibitors, monoamine oxidase type $B$ inhibitors [MAOBI and types thereof [rasagiline or selegiline, amantadine, levodopa equivalent daily dose) and MDS-modified unified Parkinson's disease rating scale (MDS-UPDRS) parts I, II, III, IV and total scores. MDS-UPDRS is the validated scale to assess patients with PD and consists of four parts: ${ }^{20}$

- Part I (non-motor experiences of daily living), which consists of 13 items. 
Table 1. Comparison of demographic and clinical characteristics of our cohort in subjects with versus without the presence of cognitive impairment symptoms $(n=306)$

\begin{tabular}{|c|c|c|c|c|c|}
\hline \multirow[t]{2}{*}{ Variable } & \multicolumn{2}{|c|}{ Cognitive impairment $(n=134)$} & \multicolumn{2}{|c|}{ No cognitive impairment $(n=172)$} & p \\
\hline & \multicolumn{2}{|c|}{ Mean \pm SD } & \multicolumn{2}{|c|}{ Mean \pm SD } & \\
\hline Age at diagnosis (years) & \multicolumn{2}{|c|}{$63.5 \pm 11.5$} & \multicolumn{2}{|c|}{$57.8 \pm 12.2$} & $<0.001$ \\
\hline Current age (years) & \multicolumn{2}{|c|}{$69.2 \pm 10.9$} & \multicolumn{2}{|c|}{$62.2 \pm 11.4$} & $<0.001$ \\
\hline Level of education (years) & \multicolumn{2}{|c|}{$8.9 \pm 5.1$} & \multicolumn{2}{|c|}{$11.8 \pm 5.1$} & $<0.001$ \\
\hline Disease duration (years) & \multicolumn{2}{|c|}{$7.6 \pm 5.3$} & \multicolumn{2}{|c|}{$5.9 \pm 4.2$} & 0.003 \\
\hline LEDD (mg) & \multicolumn{2}{|c|}{$744.0 \pm 455.9$} & \multicolumn{2}{|c|}{$739.5 \pm 499.2$} & 0.935 \\
\hline MDS-UPDRS I score & \multicolumn{2}{|c|}{$10.5 \pm 6.8$} & \multicolumn{2}{|c|}{$6.3 \pm 4.9$} & $<0.001$ \\
\hline MDS-UPDRS II score & \multicolumn{2}{|c|}{$6.3 \pm 7.0$} & \multicolumn{2}{|c|}{$4.5 \pm 4.3$} & 0.010 \\
\hline MDS-UPDRS III score & \multicolumn{2}{|c|}{$41.3 \pm 16.9$} & \multicolumn{2}{|c|}{$31.7 \pm 13.2$} & $<0.001$ \\
\hline MDS-UPDRS IV score & \multicolumn{2}{|c|}{$3.3 \pm 4.4$} & \multicolumn{2}{|c|}{$2.3 \pm 3.7$} & 0.054 \\
\hline \multirow[t]{2}{*}{ MDS-UPDRS total score } & \multicolumn{2}{|c|}{$61.5 \pm 24.3$} & \multicolumn{2}{|c|}{$44.8(18.6)$} & $<0.001$ \\
\hline & $\mathrm{n}$ & $\%$ & $\mathrm{n}$ & $\%$ & \\
\hline Females & 74 & 55.2 & 61 & 35.5 & 0.001 \\
\hline Right side symptom onset & 63 & 47.0 & 96 & 55.8 & 0.122 \\
\hline PD PIGD subtype & 78 & 58.2 & 82 & 47.7 & 0.185 \\
\hline Hoehn and Yahr stage I-III & 116 & 86.6 & 165 & 95.5 & 0.003 \\
\hline Levodopa & 115 & 85.5 & 141 & 82.2 & 0.367 \\
\hline Dopaminergic agonist & 67 & 50.0 & 92 & 53.5 & 0.545 \\
\hline MAOB inhibitor & 9 & 6.7 & 34 & 19.8 & 0.001 \\
\hline COMT inhibitor & 1 & 0.7 & 8 & 4.7 & 0.083 \\
\hline Amantadine & 26 & 19.4 & 26 & 15.1 & 0.322 \\
\hline
\end{tabular}

- Part II (motor experiences of daily living), which consists of 13 items.

- Part III (motor examination), which consists of 18 items.

- Part IV (motor complications), which consists of 6 items.

Each item of the scale is scored from 0 to 4 , where 0 is considered normal and 4, severe. At the end, the scores are added up to determine each part's total score and the scale total score. The higher the score, the worse the clinical status. In addition to demographic variables, as clinical explanatory variables, the presence of non-motor symptoms was documented using all MDS-UPDRS part I 13 items, presence of gait difficulties (MDS-UPDRS items 2.12 and 3.10) and presence of freezing of gait (items 2.13 and 3.11). To identify the presence of symptoms of cognitive impairment (categorical outcome variable), MDS-UPDRS item 1.1 was used. For purposes of the study and practice at the clinic, the presence of any symptom was recorded if the item score was 1 to 4 and absence thereof if the score was 0 .

Descriptive statistical analysis was carried out with measures of central tendency and dispersion. Means with standard deviations were analyzed for continuous variables, and frequencies with percentages were used for categorical variables. For the comparison of categorical variables, the chi-square test was used, and for variables with non-normal distribution, logarithmic transformation, as appropriate (symptom-onset side, catechol-O-methyltransferase inhibitors, type of $\mathrm{MAOBI}$ ). Assumptions of variables' distribution were 
verified with Kilmogorov-Smirnoff test. For the comparison of continuous variables means, Student's t-test was applied for variables with normal distribution (current age, age at diagnosis, level of education, MDS-UPDRS parts III, IV and total score) and log-transformation was used for variables with non-normal distribution, as appropriate (disease duration, years since diagnosis, levodopa equivalent daily dose, MDS-UPDRS parts I and II score).

In the multivariate analysis, a multiple logistic regression model was constructed to classify the patients with or without the presence of cognitive impairment symptoms. Variables with statistical significance $(p \leq 0.05)$ were included and the model with less deviation was obtained, which was constructed with $80 \%$ of the data and validated with the remaining data. For the goodness-of-fit assessment, the Hosmer-Lemeshow test was used. The calculations were carried out with the statistical program SPSS (Statistical Package for the Social Sciences), version 25.

\section{Results}

Of our total cohort of 306 subjects, 134 (43.8\%) were identified with symptoms of cognitive impairment. Table 1 describes the demographic and clinical characteristics of the study cohort, comparing subjects with and without cognitive impairment symptoms. The univariate analysis indicated that the female gender $\left(\chi^{2}\right.$ ddf $=11.9$, $\mathrm{p}=0.001)$, older age at diagnosis $(\mathrm{t}[304=4.2, \mathrm{p}<0.001)$, less years of education ( $\mathrm{t}[304=4.8, \mathrm{p}<0.001)$, longer disease duration ( $t[246.6]=2.9, p=0.003$ ), Hoehn and Yahr stage IV-V $\left(\chi_{1 \text { df }}^{2}=8.8, p=0.003\right)$, no presence of MAOBI $\left(\chi_{1 \mathrm{df}}^{2}=10.6, p=0.001\right)$ and higher total scores in MDS-UPDRS part I (t [232. $\left.{ }^{2}=6.1, p<0.001\right)$, part II (t $[209.6]=2.6, p=0.010)$, part III (t $[246.5]=5.4$, $\mathrm{p}<0.001$ ) and part IV (t $[304=6.8, \mathrm{p}<0.001$ ) were significantly associated with cognitive impairment symptoms.

Table 2 compares the presence of other non-motor symptoms based on MDS-UPDRS part I with the presence of cognitive impairment symptoms. The univariate analysis reported that the presence of symptoms of hallucinations and psychosis $\left(\left(\chi_{1 \mathrm{df}}^{2}=15.0, p<0.001\right)\right.$, depression $\left(\left(\chi_{1 \mathrm{df}}^{2}=7.2, p=0.007\right)\right.$, anxiety $\left(\chi_{1 \mathrm{df}}^{2}=12.7\right.$, $p<0.001)$, apathy $\left(\chi_{1 d f}^{2}=8.9, p=0.003\right)$, sleep disorders $\left(\chi_{1 \mathrm{df}}^{2}=4.6, p=0.031\right)$, urinary problems $\left(\chi_{1 \mathrm{df}}^{2}=\right.$ $6.8, p=0.009)$, constipation $\left(\chi_{1 \text { df }}^{2}=7.0, p=0.008\right)$, postural hypotension symptoms $\left(\chi_{1 \mathrm{df}}^{2}=5.5, p=0.019\right)$ and excessive salivation $\left(\chi_{1 \mathrm{df}}^{2}=9.8, p=0.002\right)$ were significantly associated with cognitive impairment
Table 2. Comparison of the presence of non-motor symptoms and gait impairment between subjects with vs. without cognitive impairment symptoms $(n=306)$

\begin{tabular}{|c|c|c|c|c|c|}
\hline \multirow{2}{*}{$\begin{array}{l}\text { Variable } \\
\text { Hallucinations and } \\
\text { psychosis }\end{array}$} & \multicolumn{2}{|c|}{$\begin{array}{l}\text { Cognitive } \\
\text { impairment } \\
(n=134)\end{array}$} & \multicolumn{2}{|c|}{$\begin{array}{c}\text { No cognitive } \\
\text { impairment } \\
(n=172\end{array}$} & \multirow{2}{*}{$\begin{array}{c}p \\
<0.001\end{array}$} \\
\hline & 37 & 27.6 & 18 & 10.5 & \\
\hline Depression & 89 & 66.4 & 88 & 51.2 & 0.007 \\
\hline Anxiety & 69 & 51.5 & 54 & 31.4 & $<0.001$ \\
\hline Apathy & 33 & 24.6 & 20 & 11.6 & 0.003 \\
\hline $\begin{array}{l}\text { Dopaminergic dysregulation } \\
\text { syndrome }\end{array}$ & 10 & 7.5 & 7 & 4.1 & 0.199 \\
\hline Sleep disorders & 82 & 61.2 & 84 & 48.8 & 0.031 \\
\hline Daytime sleepiness & 67 & 50.0 & 83 & 48.3 & 0.782 \\
\hline Pain & 69 & 51.5 & 82 & 47.7 & 0.507 \\
\hline Urinary problems & 87 & 64.9 & 86 & 50.0 & 0.009 \\
\hline Constipation & 82 & 61.2 & 79 & 45.9 & 0.008 \\
\hline $\begin{array}{l}\text { Postural hypotension } \\
\text { symptoms }\end{array}$ & 43 & 32.1 & 35 & 20.3 & 0.019 \\
\hline Fatigue & 86 & 64.2 & 92 & 53.5 & 0.060 \\
\hline Excessive salivation & 33 & 24.6 & 19 & 11.0 & 0.002 \\
\hline Gait disturbances & 126 & 94.0 & 144 & 83.7 & 0.005 \\
\hline Freezing of gait & 39 & 29.1 & 47 & 27.3 & 0.731 \\
\hline
\end{tabular}

symptoms. The analysis also revealed that gait disturbances (MDS-UPDRS items 2.12 and 3.10) were significantly associated with cognitive impairment symptoms $\left(\chi_{1 \text { df }}^{2}=7.7, p=0.005\right)$.

Table 3 shows the significant variables used to construct the multiple logistic regression model to predict the presence of cognitive impairment symptoms. Gender, age at diagnosis, disease duration, level of education, MDS-UPDRS part III score, symptoms of hallucinations and psychosis, anxiety and freezing of gait were significant predictors of cognitive impairment symptoms. The final model showed a $r^{2}=0.254, p=0.030$, with an accuracy of $72.5 \%$ $(95 \% \mathrm{Cl}=67.0-77.5)$.

\section{Discussion}

In a multi-center Mexican Parkinson cohort, the cognitive impairment predictive model demonstrated that the female gender, older age at diagnosis, less years of education, longer duration of disease, higher 
Table 3. Multiple logistic regression model identifying predictors of the presence of cognitive impairment symptoms.

\begin{tabular}{|l|c|c|c|c|c|c|}
\hline Variable & Coefficient $(\beta)$ & Standard error & Wald $\left(\chi^{2}\right)$ & $p$ & Exp ( $\beta)$ & $95 \% \mathrm{Cl}$ \\
\hline Constant & -5.14 & 1.11 & - & - & - \\
\hline Level of education & -0.08 & 0.03 & 8.03 & 0.005 & 0.93 & $0.88-0.98$ \\
\hline Age at diagnosis & 0.04 & 0.01 & 10.68 & 0.001 & 1.04 & $1.02-1.07$ \\
\hline MDS-UPDRS part III & 0.04 & 0.01 & 14.53 & $<0.001$ & 1.04 & $1.02-1.06$ \\
\hline Disease duration & 0.10 & 0.03 & 8.82 & 0.003 & 1.10 & $1.03-1.17$ \\
\hline Female gender & 0.57 & 0.28 & 4.34 & 0.037 & 1.77 & $1.03-3.01$ \\
\hline Freezing of gait & 0.65 & 0.33 & 3.93 & 0.048 & 1.91 & $1.01-3.64$ \\
\hline Anxiety & 0.75 & 0.28 & 7.19 & 0.007 & 2.11 & $1.22-3.64$ \\
\hline Hallucinations/psychosis & 0.82 & 0.37 & 4.79 & 0.029 & 2.27 & $1.09-4.72$ \\
\hline
\end{tabular}

MDS-UPDRS=Movement Disorder Society-Unified Parkinson's Disease Rating Scale. Our model predicts the presence of cognitive impairment symptoms with a certainty of $72.5 \%$ $(95 \% \mathrm{Cl}=67.0-77.5)$, sensitivity of $70.8 \%(95 \% \mathrm{Cl}=63.8-77.1)$, specificity of $73.7 \%(95 \% \mathrm{Cl}=69.1-77.7)$, positive predictive value of $63.4 \%(95 \% \mathrm{Cl}=57.2-69.0)$ and negative predictive value of $79.7 \%(95 \% \mathrm{Cl}=74.8-84.0)$.

MDS-UPDRS part III score and the presence of hallucinations and psychosis, anxiety and freezing of gait are significant predictors for cognitive impairment symptoms.

The results are similar to those of other previously analyzed cohorts. The prevalence of cognitive impairment symptoms in our cohort $(43.8 \%)$ is consistent with those reported in previous Mexican studies (39 to $41.3 \%)^{5,6}$ and falls within the international range (18.9 to $57.1 \%$ ). ${ }^{3,4}$ Among the predictive factors of our model, age, level of education, baseline measurements of clinical severity, disease duration, hallucinations, anxiety and freezing of gait have been reported as risk factors in international cohorts. ${ }^{12}$ The discrepancy with other investigations with regard to gender might be explained by the lower level of education in our group of female subjects in comparison with male subjects (9.51 versus $11.37, p=0.002$ ).

The univariate analysis indicated a significant association between the use of MAOBI and a lower frequency of cognitive impairment $(6.7 \%$ versus $19.8 \%$, $p=0.001$ ). However, said variable had no weight enough to be included in the final regression model. It is suggested that MAOBIs provide a benefit in cognition for its enhancing effect on dopaminergic central transmission. When the MAOBI types were separately analyzed, the use of selegiline was associated with lower presence of cognitive impairment, although not significantly $(22.2 \%$ versus $35.3 \%, p=0.693)$. Studies with rasagiline and selegiline have been limited and contradictory. Most studies with rasagiline have indicated a non-significant effect on cognition in
$\mathrm{PD},{ }^{21-24}$ and most studies with selegiline, although positive, are few and of limited epidemiological design. ${ }^{25-27}$ Selegiline probable positive effect on cognition might be explained by its action on monoaminergic systems. ${ }^{28}$ We consider that prospective studies on cognition in PD are needed to confirm the effect of MAOBIs, specifically of selegiline.

The present study has several limitations. The sample calculation was by convenience, and it is therefore subject to bias and may have influenced the final model. Since the type of study entails limitations, to reduce associated bias and control for possible confounding variables, we constructed an analytical regression model. We tried to reduce the selection bias by including a multicenter cohort. The measure used to classify the presence of non-motor symptoms, specifically cognitive impairment, is not the most adequate for this purpose. We did not consider other reported risk factors for cognitive impairment in Parkinson such as genetic factors, thinning of the cerebral cortex, amyloid accumulation or cerebral white matter lesions. However, the results raise the possibility of carrying out prospective studies to assess the factors associated with cognition in PD that we identified.

\section{Conclusions}

Our results identified risk factors for the presence of cognitive impairment symptoms that are consistent with those reported in previous studies. Apparently, the female gender was more affected in our cohort 
owing to its lower level of education. Prospective studies are required to clarify the effect of MAOBIs on the cognition of patients with PD.

\section{References}

1. Kalia LV, Lang AE. Parkinson's disease. Lancet. 2015;386:896-912.

2. Seppi K, Ray-Chaudhuri K, Coelho M, Fox SH, Katzenschlager R, Perez-Lloret S, et al. Update on treatments for nonmotor symptoms of Parkinson's disease-an evidence-based medicine review. Mov Disord. 2019:34:180-198.

3. Aarsland D, Bronnick K, Larsen JP, Tysnes OB, Alves G, Norwegian ParkWest Study G. Cognitive impairment in incident, untreated Parkinson disease: the Norwegian ParkWest study. Neurology. 2009;72:1121-1126.

4. Williams-Gray $\mathrm{CH}$, Foltynie $\mathrm{T}$, Brayne $\mathrm{CE}$, Robbins TW, Barker RA Evolution of cognitive dysfunction in an incident Parkinson's disease cohort. Brain. 2007;130:1787-198.

5. Rodríguez-Violante M, Cervantes-Arriaga A, Villar-Velarde A, Corona T. Prevalence of non-motor dysfunction among Parkinson's disease patients from a tertiary referral center in Mexico City. Clin Neurol Neurosurg. 2010;112:883-885

6. Isaís-Millán S, Piña-Fuentes D, Guzmán-Astorga C, Cervantes-Arriaga A Rodríguez-Violante M. Prevalence of neuropsychiatric disorders in drug-naive subjects with Parkinson's disease (PD). Gac Med Mex. 2016;152:357-363.

7. Muslimovic D, Post B, Speelman JD, Schmand B. Cognitive profile of patients with newly diagnosed Parkinson disease. Neurology. 2005;65:1239-1245.

8. Litvan I, Aarsland D, Adler CH, Goldman JG, Kulisevsky J, Mollenhauer B et al. MDS Task Force on mild cognitive impairment in Parkinson's disease: critical review of PD-MCI. Mov Disord. 2011;26:1814-1824.

9. Aarsland D, Bronnick K, Ehrt U, De Deyn PP, Tekin S, Emre M, et al. Neuropsychiatric symptoms in patients with Parkinson's disease and dementia: frequency, profile and associated care giver stress. J Neurol Neurosurg Psychiatry. 2007;78:36-42.

10. Levy G, Tang MX, Louis ED, Coté LJ, Alfaro B, Mejia H, et al. The association of incident dementia with mortality in PD. Neurology. 2002;59:1708-1713.

11. Uc EY, McDermott MP, Marder KS, Anderson SW, Litvan I, Como PG et al. Incidence of and risk factors for cognitive impairment in an early Parkinson disease clinical trial cohort. Neurology. 2009;73:1469-1477.

12. Liu G, Locascio JJ, Corvol JC, Boot B, Liao Z, Page K, et al. Prediction of cognition in Parkinson's disease with a clinical-genetic score: a longitudinal analysis of nine cohorts. Lancet Neurol. 2017;16:620-629.

13. Hu MT, Szewczyk-Krolikowski K, Tomlinson P, Nithi K, Rolinski M, Murray $\mathrm{C}$, et al. Predictors of cognitive impairment in an early stage Parkinson's disease cohort. Mov Disord. 2014;29:351-359.
14. Schrag A, Siddiqui UF, Anastasiou Z, Weintraub D, Schott JM. Clinical variables and biomarkers in prediction of cognitive impairment in patients with newly diagnosed Parkinson's disease: a cohort study. Lancet Neurol. 2017;16:66-75.

15. Liu G, Boot B, Locascio JJ, Jansen IE, Winder-Rhodes S, Eberly S, et al Specifically neuropathic Gaucher's mutations accelerate cognitive decline in Parkinson's. Ann Neurol. 2016;80:674-685.

16. Pereira JB, Svenningsson P, Weintraub D, Bronnick K, Lebedev A, Westman E, et al. Initial cognitive decline is associated with cortical thinning in early Parkinson disease. Neurology. 2014;82:2017-2025.

17. Melzer TR, Watts R, MacAskill MR, Pitcher TL, Livingston L, Keenan RJ, et al. White matter microstructure deteriorates across cognitive stages in Parkinson disease. Neurology. 2013;80:1841-1849.

18. Gomperts SN, Locascio JJ, Rentz D, Santarlasci A, Marquie M, Johnson KA, et al. Amyloid is linked to cognitive decline in patients with Parkinson disease without dementia. Neurology. 2013;80:85-91.

19. Postuma RB, Poewe W, Litvan I, Lewis S, Lang AE, Halliday G, et al. Validation of the MDS clinical diagnostic criteria for Parkinson's disease. Mov Disord. 2018;33:1601-1608.

20. Goetz CG, Tilley BC, Shaftman SR, Stebbins GT, Fahn S, Martinez-Martin P, et al. Movement Disorder Society-sponsored revision of the Unified Parkinson's Disease Rating Scale (MDS-UPDRS): scale presentation and clinimetric testing results. Mov Disord. 2008;23:2129-2170.

21. Frakey LL, Friedman JH. Cognitive effects of rasagiline in mild-to-moderate stage parkinson's disease without dementia. J Neuropsychiatry Clin Neurosci. 2017:29:22-25.

22. Weintraub D, Hauser RA, Elm JJ, Pagan F, Davis MD, Choudhry A, et al. Rasagiline for mild cognitive impairment in Parkinson's disease: a placebo-controlled trial. Mov Disord. 2016;31:709-714.

23. Dashtipour K, Chen JJ, Kani C, Bahjri K, Ghamsary M. Clinical outcomes in patients with Parkinson's disease treated with a monoamine oxidase type-B inhibitor: a cross-sectional, cohort study. Pharmacotherapy. 2015;35:681-686.

24. Hanagasi HA, Gurvit H, Unsalan P, Horozoglu H, Tuncer N, Feyzioglu A, et al. The effects of rasagiline on cognitive deficits in Parkinson's disease patients without dementia: a randomized, double-blind, placebo-controlled, multicenter study. Mov Disord. 2011;26:1851-1858.

25. Shoulson I. Deprenyl and tocopherol antioxidative therapy of parkinsonism (DATATOP). Parkinson Study Group. Acta Neurol Scand Suppl. 1989;126:171-175

26. Dixit SN, Behari M, Ahuja GK. Effect of selegiline on cognitive functions in Parkinson's disease. J Assoc Physicians India. 1999:47:784-786.

27. Dalrymple-Alford JC, Jamieson CF, Donaldson IM. Effects of selegiline (deprenyl) on cognition in early Parkinson's disease. Clin Neuropharmacol. 1995;18:348-359.

28. Knoll J. (-)Deprenyl (selegiline), a catecholaminergic activity enhancer (CAE) substance acting in the brain. Pharmacol Toxicol. 1998;82:57-66. 